Running head: OPEN DIALOGUE: GOOD AND POOR OUTCOME

Journal of Constructivist Psychology, 14:267-284, 2001

Address correspondence to Jaakko Seikkula, Ph.D., Department of Psychology, University of Jyvaeskylae, P.O.Box 35, FIN - 40351 Jyvaeskylae, Finland; e-mail: seikkula@psyka.jyu.fi

\title{
Open Dialogue in Psychosis II: A Comparison of Good and Poor Outcome Cases
}

\author{
Jaakko Seikkula \\ University of Jyväskylä \\ and University of Tromso \\ Birgitta Alakare \\ Western Lapland Health District, Tornio \\ and University of Oulu \\ and \\ Jukka Aaltonen \\ University of Jyväskylä
}

\begin{abstract}
As an approach to treatment of psychosis, Open Dialogue aims to begin treatment within 24 hours of first contact between the health system and the patient or family, and in accordance with social constructionist principles, includes the family and the social network in open discussion of all issues throughout treatment. As one step toward evaluating the impact of this novel model of care, statistical and qualitative analyses of 78 consecutive first-episode psychotic cases was undertaken, discriminating good from poor outcome cases on the basis of functional and symptomatic criteria. Results suggested differences in the diagnosis and duration of prodromal and psychotic symptoms, as well as in treatment processes in the two groups. Avoiding hospitalization and using anxiolytics instead of neuroleptics were associated with a good outcome. Overall, data bearing on the effectiveness of OD were encouraging, as only $22 \%$ poor outcome patients emerged. However, if the possibility for starting a dialogical process is minimal, the treatment may lead to poor outcome, even where this is not predicted by premorbid social and psychological factors.
\end{abstract}


In the preceding paper, we have outlined a novel approach to the treatment of serious psychotic disturbances, one predicated largely on a constructivist view that psychotic symptoms are meaningful, and a social constructionist perspective that encourages joint conversation about such difficulties within local communities of concern (Seikkula, Alakare \& Aaltonen, 2001). Our aim in the present paper is to document the outcomes of this approach, termed Open Dialogue (OD), in the hope of identifying factors associated with favorable and unfavorable response to such treatment. To provide a background for this effort, we will first summarize what is currently known about the prediction of outcome in psychosis, describe predominant approaches to treatment, and then situate our own research in the context of this literature.

\section{Predictors of Outcome in Psychosis: Clues from the Literature}

Psychological factors. The main factors related to outcome in first episode psychosis have consisted of psychological variables, premorbid social and occupational adjustment, duration of untreated psychotic and prodromal symptoms, and variables relating to the treatment process itself. Depression (Jackson \& Birchwood, 1996) and, more accurately, hopelessness at the onset of a psychotic crisis has been connected to both earlier relapse and a higher suicide rate (Caldwell\& Gottesman, 1990), and to poorer short term outcome and worse global functioning after one year (Aguilar, Haas, Manzanera, Hernandez, Gracia et al., 1997). Likewise, a lower global adjustment rating and higher rating of psychotic symptoms have been connected with the progression from minor prodromal symptoms to psychotic symptoms during a one-year period (Yung, Phillips, McGorry, Hallgren, McFarlane et al., 1998). In particular, early negative symptoms have been found as predictor of poor outcome ( Jackson\& Birchwood, 1996; Scottish Schizophrenia Research group, 1988 ). Individuals' cognitive impairments have been associated with the outcomes of their illnesses and with the efficacy of skills training (Mueser, Wallace \& Liberman, 1995).

Social factors. Beyond these individual factors, the social network of schizophrenia patients has been found to differ from the normal population and from those with affective psychosis (Erickson, Beiser, Iacono, Fleming, \& Lin, 1989). The nature of relationships was a more important predictor of short-term outcome among schizophrenia patients than among affective psychotic patients. In their first contact with the health care system, schizophrenia patients had fewer non-kin members present, which was negatively associated with outcome. After approximately a three years treatment, the social network was smaller and less reciprocal and contained fewer family members compared to patients whit less severe problems (Meeks \& Murrell, 1994). The network was more likely to include social service providers, but these relations were non-reciprocal, which meant the patient being helped by others while they themselves did not give aid reciprocally. Patients with low non-family social contacts tended to relapse earlier (Johnstone, Frith, Crow, Owen, Done et al., 1992). These differences may be due more to the treatment history than diagnosis, since among first episode patients the size of the social network was much the same as in the population in general (Seikkula, 1991). The subjects at risk of schizophrenia had significantly poorer social competence and more formal thought disorders (Dworkin, Green, Small, Warner, Cornblatt et al., 1990). Poor work and occupational adjustment prior to the first hospitalization has also predicted poor outcome (Bean, Beiser, Jiahui, \& Iacono, 1996)

Mean duration of psychotic symptoms before the first treatment sequence has been approximately one year (Barnes, Hutton, Chapman, Mutsatsa \& Joyce, 2000; 
Loebel, Lieberman, Alvir, Mayerhoffer, Geisler et al., 1992), but the prodromal signs may have existed for the preceding three years, which has been seen as the single most powerful predictor of poor outcome ( Lieberman, 1997). The longer the duration of symptoms, the poorer the outcome in all cases. Long duration of non-psychotic prodrome was the strongest predictor of negative attribution made by significant others (Bean et al., 1996). The main barriers against entering treatment have been a poor social network and withdrawal from social contacts (Larsen, Johannessen, \& Opjordsmoen, 1998). In some cases the misinterpretation of early symptoms in primary care could delay treatment.

\section{Trends in Treatment}

Pharmacological treatment. Neuroleptic medication has been seen as the primary component of psychosis therapy (Lehman, Steinwachs et al., 1998; Liberman, 1993). As a recommendation, it should be used as first line treatment to reduce psychotic symptoms and dosages should be about 300 - $500 \mathrm{mg}$ chlorpromazine in first episode cases. Massive loading doses are not recommended. Some studies, conducted in combination with advanced psychosocial treatment, have shown that the doses of anti-psychotic medication can be reduced and outcomes seem to improve (McGorry, Edwards, Mihalopoulos, Harrigan, \& Jackson, 1996). Some recent studies have shown that anti-psychotic medication on the whole can be avoided in about half of cases with a similar result to that obtained following the use of medication (Ciompi,Dauwalder, Maier, \& Aebi, 1992; Cullberg, Thoren, Åbb, Mesterton, \& Svedberg, 1999; Lehtinen, Aaltonen, Koffert, Räkkölöinen, \& Syvälahti, 2000). In these studies, anxiolytics were used as the primary medication, and low doses of neuroleptics are preferred. The risk factor in non-medication studies has been higher relapse rates (Carpenter, 1997). In placebo control trials relapse rates have been about $50 \%$. Recently, criticism has been levelled at study designs emphasising the importance of neuroleptic medication (Jackson \& Birchwood, 1996; Greenberg, 1999). For example, occupational outcome after two years may be worse if neuroleptic medication compared to a placebo was used (Jackson \& Birchwood, 1996; Johnstone, Macmillan, Frith, Benn, \& Crow, 1990). Lieberman (1997) found that 86 $\%$ of schizophrenic patients recovered from psychosis during the first year, but $78 \%$ of these relapsed at least once after an initial recovery. He recommended that patients be kept on the same anti-psychotic medication regimen for an additional period.

Psychosocial treatment. In studies of treatment outcomes, the integration of different psychosocial methods has been emphasized. In a program with young psychotic patients, McGorry (1996; McGorry et al., 1996, 1998) emphasized taking into account the adaptive and healthy elements of the patient. Psycho-educational family programs in combination with medication have been found to be effective for first- or recent-onset schizophrenic patients during the stabilisation phase of treatment (Goldstein, 1996). Likewise, cognitive skills training and cognitive-behavior therapy have been seen as viable in serious psychotic situations (Eckman, Wirsching, Marder, Liberman, Johnston-Cronk et al., 1992; Liberman, 1993; Liberman and Green, 1992; McFarlane, Link, Dushay, Matchal, \& Crilly, 1995; Mueser et al., 1995; Wirsching, Marder, Eckman, Liberman, \& Mintz, 1992;) and also with difficult-to-treat patients without medication (Kuipers, 1996). However, a decrease in the effectiveness of family psycho-education and social skills training against late relapse has been observed in the second year after discharge from such programs (Hogarty, Kornblith, Greenwald, DiBarry, Cooley et al., 1997). Linszen, Dingemans, Scholte, Lenior and Goldstein (1998) did not find support for the overall benefit of a family psychoeducational program compared with the use of standard individual therapy alone. In 
their follow-up (Linszen, Lenior, De Haan, Dingemans \& Gersons, 1998) the problem became one of the discontinuity of the process, which caused relapses in $64 \%$ of cases. Whereas personal therapy focused on the management of affect dysregulation was effective with patients living with their families, those living independently showed more psychotic relapse (29\%), and more premature termination (18\%) of treatment.

As a response to the limitations of traditional individual treatment programs, some investigators have proposed more socially-focused approaches to the treatment of psychosis. For example, Ciompi's (1992) open residential program provided acute schizophrenic patients with psychotherapy, socio-therapy, and milieu-therapy instead of standard pharmaco-therapy. Alanen's Need-Adapted treatment (1997; Alanen, Lehtinen, Räkköläinen, \& Aaltonen, 1991; Lehtinen, 1993) integrated various psychotherapeutic methods in the same program. The need for hospitalization in first episode cases decreased, but problems were encountered in achieving continuity of treatment between hospital and outpatient services (Lehtinen, 1993).

\section{The Development of Open Dialogue}

The Open Dialogue Approach (OD) has its origins in the Finnish schizophrenia psychotherapy tradition and, especially, in the Need-Adapted model (Alanen, 1997). In Western Lapland, the basic idea behind the family- and networkcentred treatment system is to organise psychotherapeutic management for all patients within their own social support network (Seikkula, Aaltonen, Alakare, Haarakangas, Keränen et al., 1995; Seikkula, Alakare, Aaltonen, 2001). The same procedure is followed in any crisis, regardless of the diagnosis. To implement this system of treatment, all members of the staff, totalling about 100 professionals (both inpatient and outpatient staff), participated in either a three year family therapy training program or some other form of psychotherapy training. A qualification as a psychotherapist according to the Finnish law, was obtained by $75 \%$ of the staff.

This article describes the results of a programme designed for first episode psychotic patients. The study is part of a Finnish national multicenter project, the Integrated Approach to the Treatment of Acute Psychosis (API) with six research centres altogether. The project has been carried out since its inception 1992 by the National Research and Development Center for Welfare and Health (STAKES) in conjunction with the Universities of Jyväskylä and Turku. Western Lapland, as one of three centres, was allotted the specific task of organizing treatment by minimizing the use of neuroleptic medication. (Lehtinen et al., 1996).

The goal of this study was to evaluate the problems and prospects of OD in first episode psychosis by comparing good and poor outcome patients at two-year follow-up. The first objective was to clarify the variables relating to premorbid adjustment and treatment process. The second objective was to analyse the therapeutic means employed in each type of case, focusing on the seven OD principles described by Seikkula et al. (2001). They are briefly summarised in Table 1 . This study includes a preliminary qualitative and statistical analysis, which will be followed by a deeper process analysis of the dialogue involved.

$\underline{\text { Participants }}$

\section{Methods}

All the new cases in the region that fulfilled the DSM-III-R criteria for schizophrenia-type psychosis between 1 April 1992 and 31 March 1997 were included. The local ethical committee gave permission for the study. Every patient was asked to give his/her consent to inclusion. Altogether 90 patients started treatment. Five refused to participate in the study (four of these were diagnosed as 
having a reactive psychosis and one as having a prodromal form of schizophrenia), and two treatments were started according to other treatment principles than OD (diagnoses of schizophreniform psychosis and psychosis NOS). One of these treatments began with individual psychotherapy for three months in a clinic not included in the project. Although the family contacted the local outpatient clinic, the patient committed suicide before the team had the opportunity to meet her. During the two-year follow-up period three patients committed suicide (two cases diagnosed as schizophrenia, one as schizophreniform psychosis). All these latter cases occurred during the same year (1995) in the same geographical part of the district (Kemi area), where, during this particular year, the suicide rate among the general population in the area was three times higher than usual. All three patients had recovered from their psychotic symptoms and were on continuing neuroleptic medication and in individual psychotherapy. In two cases (diagnosed as schizophreniform psychosis and brief psychotic episode), it was not possible to conduct a reliable enough analysis of psychotic symptoms at the follow-up and hence they were excluded. This report is based on complete data for 78 patients, of which 31 were female and 47 male, their mean age being 26.5 years without any significant difference between male and female patients.

Procedure

During the first three weeks, the patients were assessed on a Brief Psychiatric Ratings Scale (BPRS) and Global Assessment of Function Scale (GAF). The severity of psychotic symptoms was scored on a 5-point sub-scale of the Strauss and Carpenter (1972) instrument ( $0=$ no symptoms; $1=$ mild symptoms almost all the time or moderate occasionally; $2=$ =moderate symptoms for some time; $3=$ =prominent symptoms for some time or moderate symptoms all the time; $4=$ continuous prominent symptoms). The ratings were scored jointly by the treatment team together with one of the authors (JS or BA) who, as researchers, were not involved in the particular treatment process. The diagnosis was made in two phases. After the first meeting, the team, jointly with the chief psychiatrist (author BA), constructed the first hypothesis, and after six months, having also interviewed the patients individually, she made the final diagnosis. To analyse the social network of each patient this same author held a confidential interview with that patient. During the first treatment meetings, the family was interviewed about the duration of psychotic and prodromal symptoms before the first contact. Author BA verified this during the confidential interview with the patient. The ratings and the analysis of the patient's social network were repeated in the two-year follow-up interview, which was conducted in the presence of both the treatment team and the family. At this interview the main theme was the realisation of the seven OD principles (Table 1). First, the patient and the family were interviewed, after which the team commented on what the family had said and reported their own experiences and, in the final phase, the family members gave their comments on what they felt was important. After the follow-up interview, authors BA and JS scored the realisation of each principle on a scale of $0-3 ; 0=$ realized adequately; $1=$ realized in the main, but with small exceptions; $2=$ partially realized; $3=$ not realized. Both authors first made their own suggestions and then a consensus was negotiated.

To serve the study aims two groups were formed: (1) a Poor outcome group $(\mathrm{N}=17)$, consisting of those patients whose source of living was a disability allowance $(n=13)$ or with residual moderate or more severe psychotic symptoms (rated as 2 or 3 on the Strauss \& Carpenter scale, $n=4)$; and (2) the Good outcome group ( $N=61$ ), consisting of those patients who were working, studying or job-seeking with no more than mild residual psychotic symptoms $(n=7)$. Thus the distinction was based on 
functional criteria with practical implications for the patient's quality of life.

\section{Results}

$\underline{\text { Statistical analysis }}$

In Table 2 the premorbid adjustment of the patients in the good and poor outcome groups are compared. Significant differences emerged in employment status and in quality of the social network before the psychotic crisis. If the patients had been living passively without searching for a job, they were more likely to have a poor outcome after two years. There were, however, many exceptions to this. Most of the patients with a poor outcome at the two-year follow-up did not have problems in their occupational history before the crisis. Three of the patients who were living passively at the onset of the crisis had a better occupational situation at the two-year follow-up.

At the onset, the symptoms ratings (GAF, BPRS; Table 3) did not differ between the patients in the two groups. Significant differences emerged in the duration of both psychotic (DUP) and prodromal symptoms prior to treatment. All the patients with a poor outcome had been diagnosed as either schizophreniform or schizo-affective psychosis or schizophrenia.

The Poor outcome group was more likely to have had a poor social network either at the onset with no change during the treatment period or to show further impoverishment during the two-year period (Table 4). There were, however, exceptions to this general trend. Three of the poor outcome patients did show a positive development in their social network and, vice-versa, eleven patients had a good outcome regardless of the impoverishment of their social network. After the two-year follow-up, however, quality of social network seems to have been connected with treatment processes. Two out of three with a poor outcome at the two-year follow-up and with improvement on the quality of their social network had made considerable progress by the five-year follow-up point.

Poor outcome patients were hospitalised for a longer time and were more likely to have used neuroleptic medication. This is a remarkable result, as 57 patients (73.1\%) had not used neuroleptic medication at all and of those patients only 8 (14\%) were defined as Poor outcome cases. Of these eight patients who were not taking neuroleptics, four had declined such medication and in four cases it had not been evaluated as necessary because these patients did not have severe psychotic symptoms.

Case analysis

Case1. Good outcome and an intensive treatment process; Psychotic symptoms $=4$ at the outset; $=0$ at follow-up

Lisa's twin brother had been brought into primary care during the weekend following a suicide attempt. On Monday morning his general practitioner contacted a psychologist at the local mental health outpatient clinic. He organized a team consisting, in addition to himself, of a nurse from the outpatient clinic and a doctor and a psychologist from the hospital's crisis clinic. The team made a home visit the same day. Present at the first meeting were Lisa, her mother, father, twin brother and a younger brother. Lisa started to talk about her own personal philosophical theories and about her delusions of seeing people with the head of a bull. The team tolerated this unexpected story and started to talk with Lisa and the rest of the family. They were somewhat surprised as they were under the impression that they had come for Lisa's twin brother, but her mother told them that at home they were worried about both siblings. It emerged that both were in fact severely psychotic. Lisa had returned home one year earlier and both twins had isolated themselves during the preceding 
four-month period. Lisa had had psychotic symptoms for 25 months. She was evaluated at the outset as having a poor social network.

Treatment meetings were organized daily at the beginning and during the first two months nine meetings were organized altogether. The meetings developed an increasingly psychotherapeutic quality and many episodes of reflective discussion between the team members emerged. In the sixth and seventh meetings Lisa expressed anger and hatred towards her father owing to her perceptions of his behaviour during their childhood. It seemed that for the first time it had become possible for her to construct words to describe her difficult experiences with her father.

At the beginning of the process, the general practitioner prescribed neuroleptics, which Lisa tried to take on five occasions but eventually decided to discontinue because, as she said in the two year follow-up interview, "all the world became dark and immobile, I did not have any thoughts left". After two months, individual psychotherapy was started with a psychologist who was a member of the crisis team. This was done in a joint understanding after being proposed by the team. The team members took the view that after the acute crisis was over, more systematic psychotherapy would be needed. During this phase, Lisa still occasionally had prominent psychotic experiences. After six months Lisa decided to stop the psychotherapy, moved away from home and could not be contacted. In the two-year follow-up interview she said that she had started to study philosophy and that she had no remaining psychotic symptoms. She had decided that she herself had to find a way out of her problems, and that was why she discontinued the psychotherapy and moved away. She also said that she had realized that it was not good for her to live near her family, since this easily led to quarrels. It was better for her to live without too many contacts with her family. She had had psychotic delusions for about half a year after discontinuing the psychotherapy, but since then the symptoms had not re-occurred. In the five-year follow-up interview she said that she had taken a break from her studies. She had been working as a full time cleaner for three years time, was married and talked about their plans to have a baby.

The seven principles had been realized to an adequate extent. The first meeting had taken place immediately on the same day after the contact with the general practitioner and the closest social network was involved from the outset, although the motivation of the parents subsequently declined. The same team guaranteed psychological continuity throughout the process, including the shift from family sessions to individual psychotherapy. The process allowed for tolerance of the uncertain periods of hallucinatory talk and the hatred Lisa expressed towards her father. During the many critical phases of the process, the dialogue was generated and maintained. This was already evident at the first meeting, in which the team did not focus on diagnosing the psychosis, but rather emphasised generating a dialogue in which the family could present the problem in their own language.

Case 2. Poor outcome, prominent psychotic symptoms in the follow-up;

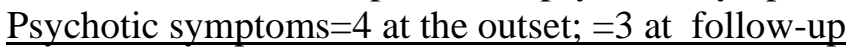

Matti returned home after a three-year period of employment and reported people listening in to his telephone, and trying to poison him. His mother brought him to the hospital's crisis clinic and asked for help. At his point, however, Matti was very coherent, saying that he had himself found the solution to his problems and rejected the proposed home visit the next day. He was evaluated as having a normal social network, and his psychotic symptoms had continued for two months. 
One month later, a general practitioner in the local health center contacted the crisis clinic reporting that Matti had severe psychotic problems. An intense process of discussing the crisis with the whole family was started, but during this process Matti ceased to have almost any communication with the outside world. Five months later he began to refuse to eat and, developing an infection, was hospitalised for a month. A course of anti-depressant medication was started and, mainly on account of his family's wish, he was discharged and returned home where the treatment meetings continued. He was hospitalised for 34 days. After one year of treatment, neuroleptic medication was prescribed. After a one and a half years in a crisis situation involving his sister, Matti suddenly improved, started two occupational training courses one after the other and decided of his own volition to discontinue medication. After this he "slipped" into speechlessness and limited communication. It was during this phase that the two-year follow-up interview was conducted. Treatment meetings were organized every second week throughout the follow-up period. A rehabilitation program was also planned for him. This included, for instance, an occupational training course for three months, which he took.

Matti's treatment was at all times very difficult and no joint understanding of the problem emerged. Considerable problems existed already at the outset because of the one-month's delay after the first treatment meeting at the crisis clinic. Medication seemed to help at one point during treatment, but not permanently. The main treatment always took the form of an intensive effort to achieve psychotherapeutic understanding, but without success. On the whole, problems emerged in meeting many of the OD principles. Both immediate help and psychological continuity became problematic when, after the first meeting, the team did not succeed in motivating the family in favour of treatment. Perhaps the team did not notice the severity of the situation and did not hear the worry expressed by Matti's mother clearly enough at the very first meeting. Flexibility was not realized in the sense that disagreement often occurred between the team and the family, which meant that abrupt changes in Matti's condition forced actions to be taken rather than allowing them to emerge from a joint process. The team tolerated uncertainty and shared the disappointment of the family because no improvement in Matti's situation was achieved, but a dialogical process was not realized. This was partly because of the concrete language used by the family. The team did not find a way to construct a process that would have suited the language of the family.

\section{Discussion}

With the goal of developing OD, the aim of this study was to analyse the problems involved by comparing the good and poor outcome patients. Both statistical and qualitative data were used. The main problem with this type of study design is to create robust criteria for good and poor outcome. In the present study this was done in a pragmatic way - by studying how well the individuals have been able to return to their active social life and the extent to which they had residual psychotic symptoms.

Statistically, the results were in line with those of most current studies, except concerning the importance of neuroleptic medication. Employment status and quality of social network were the most powerful premorbid characteristics related to a poor outcome. In this study, fewer poor outcome patients (22\%) emerged in comparison to many other studies (Gupta, Andreasen, Arndt \& Flaum, 1997). This may be a result of the active orientation to the patient's social network. The patients were encouraged to return their active social life and their social contacts were supported.

Diagnosis and duration of both prodromal and psychotic symptoms were the psychological status characteristics that had the closest connection with a poor 
outcome. The mean of DUP has decreased to under 4 months, as has been the case in some other advanced psycho-social programs as well (McGorry et al., 1996: Yung et al., 1998). This is a good result as such, and may be reflected in the rather good employment status after two years.

Poor outcome patients were hospitalised more, and they were more likely to be using neuroleptic medication. This in itself does not serve as any basis for a causal explanation, because the research design included the objectives of as far as possible avoiding hospitalization and minimising neuroleptic medication. In this design, hospitalization and neuroleptic medication were intended to be used in only the most severe cases. It is interesting, however, to note that in the beginning phase of treatment the patients did not differ in initial symptomatology (BPRS rating) and overall function (GAF ratings) and that good outcome patients actually made less use of medication. The basic difference consisted of the longer duration of pre-existing symptomatology, which makes the use of neuroleptics easier. This suggests the possibility that treatment initiated without neuroleptics can promote good outcome after two years, presupposing an adequate psychosocial treatment, such as that which OD provides. The results suggest that in case of active family-centred treatment the use of neuroleptic medication can be decreased without increasing the risk of poor outcome. It remains for further research to determine whether, on the whole, the use of neuroleptic medication can in some cases even increase the risk for poor employment status and thus for poorer outcome.

In the qualitative analysis of two cases it was noted that the statistical differences found did not, as such, predict poor outcome. In clinical practice, the different variables have a co-evolutionary effect, such that, in spite of their shortcomings an adequate process of treatment can be started, provided that a constructive dialogue between the team and the patient and his/her social network can be started (see case 1). If the possibility of starting a dialogical process is minimal, the treatment may lead to poor outcome, even when this is not predicted by the premorbid social and psychological adjustment (case 2). The main problem of OD seemed to be organizing treatment in cases in which the family had few possibilities for developing a linguistic description of their life. To help families in this situation, both new methods and analyses of the quality of the dialogue in treatment meetings are needed to develop the team's ability at constructing dialogue. This is a major objective for further research. The principles of OD seem to provide a useful set of guidelines for analysing the treatment process, even though conforming to them did not as such predict the outcome. 


\section{References}

Aaltonen, J., Seikkula, J., Alakare, B., Haarakangas, K., Keränen, J., \& Sutela, M. (1997). Western Lapland project: A comprehensive family- and network centered community psychiatric project. ISPS. Abstracts and lectures 12-16 October 1997. London

Aguilar, E., Haas, G., Manzanera, F., Hernandez, J. Gracia, R., Rodado, M. \& Keshavan, M. (1997) Hopelessness and first episode psychosis: A longitudinal study. Acta Psychiatrica Scandinavica, 96, 25-30.

Alanen, Y. (1997). Schizophrenia. Its origins and Need-Adapted Treatment. London. Karnac Books.

Alanen, Y., Lehtinen, K., Räkköläinen, V. \& Aaltonen, J. (1991). Needadapted treatment of new schizophrenic patients: Experiences and results of the Turku Project. Acta Psychiatrica Scandinavica, 83, 363-372.

Anderson C., Hogarty G. \& Reiss D. (1980). Family treatment of adult schizophrenic patients: A psycho-educational approach. Schizophrenia Bulletin, 6, 490-505.

Barnes, T., R., Hutton, R., Chapman, M., Mutsatsa, B. \& Joyce, E.M. (2000). West London first-episode study of schizophrenia. Clinical correlates of duration of untreated psychosis. British Journal of Psychiatry, 177, 207-211.

Bean, G., Beiser, M., Jiahui, Z-W. \& Iacono, W. (1996). Negative labelling of individuals with first episode schizophrenia: the effect of premorbid functioning. Schizophrenia Research, 22, 111-118.

Birchwood, M. (1999). Early intervention in psychosis: The critical period. In P. McGorry \& H. Jackson (eds.) The recognition and management of early psychosis. Cambridge. Cambridge University Press.

Caldwell, J. \& Gottesman, L. (1990). Schizophrenics kill themselves too. Schizophrenia Bulletin, 16, 571-590.

Carpenter, W.(1997). The risk of medication-free research. Schizophrenia Bulletin, 23,11-18.

Ciompi, L., Dauwalder, H-P., Maier, C. \& Aebi, E. (1992). The Pilot project "Soteria Bern". Clinical experiences and results. British Journal of Psychiatry, 161 (Suppl 18), 145-153.

Cullberg, J., Thoren,G., Åbb,S., Mesterton, A. \& Svedberg, B. (1999). Integrating intensive psychosocial and low dose medical treatment in a total material of first episode psychotic patients compared to "treatment as usual”. A 3-year followup. In Martindale, B., Bateman,T., Crowe, M. and Margison, F. (eds.) Outcome studies in psychological treatments of psychotic conditions. London, Gaskell Press.

Dworkin,R., Green, S., Small, N., Warner, M., Cornblatt, B. \& ErlernmeyerKimling, L. (1990) Positive and negative symptoms and social competence in adolescents at risk for schizophrenia and affective disorder. American Journal of Psychiatry. 147, 1234-1236.

Eckman,T., Wirsching,W., Marder,S., Liberman,R., Johnston-Cronk,K., Zimmerman,K. \& Mintz,J. (1992). Technique for training schizophrenia patients in illness self-management: a controlled trial. American Journal of Psychiatry, $\underline{149}, 1549-1555$.

Erickson, D., Beiser, M., Iacono, W., Fleming, J. \& Lin T. (1989) The role of social relationships in the course of first-episode schizophrenia and affective psychosis. American Journal of Psychiatry. 146, 1456-1461. 
Gleeson, J., Jackson, H., Stavely, H. \& Burnett, P. (1999). Family intervention in early psychosis. In P. McGorry \& H. Jackson (eds.) The recognition and management of early psychosis. Cambridge. Cambridge University Press.

Goldstein, M. (1996). Psycho-education and family treatment related to the phase of a psychotic disorder. Clinical Psychopharmacology, 11(Suppl 18), 77-83.

Greenberg, R. (1999). Common psychosocial factors in psychiatric drug therapy. In M. Hubble, B. Duncan \& S.D. Miller (Eds) The heart \& soul of change. What works in therapy. Washington, DC. American Psychological Association

Gupta S, Andreasen N, Arndt S \& Flaum M. (1997). The Iowa longitudinal study of recent onset schizophrenia: One-year follow-up of first episode patients. Schizophrenia Research, 23 (1),1-13.

Hogarty, G., Kornblith,S., Greenwald,D., DiBarry,A., Cooley, S., Ulrich,R., Carter,M. \& Flesher, S (1997) Three-year trials of personal therapy among schizophrenic patients living with or independent of family, I: Description of study and effects on relapse rates. American Journal of Psychiatry. 154, 1504-1513.

Jackson, C. \& Birchwood, M. (1996). Early intervention in psychosis: Opportunities for secondary prevention. British Journal of Clinical Psychology, 35, 487-502.

Jackson, H., McGorry, P. \& Dudgeon, P. (1995). Prodromal symptoms of schizophrenia in first-episode psychosis: Prevalence and specificity. Comprehensive Psychiatry, 36, 241-250.

Johnstone, E., Macmillan,F., Frith, C., Benn, D. \& Crow, D.(1990). Further investigation of the predictors of outcome following first schizophrenic episode. British Journal of Psychiatry, 157, 182-189.

Johnstone, E., Frith, C., Crow, D., Owen, D., Done, D., Baldwin, E \& Charlette, A. (1992). The North Park Functional Psychosis Study: Diagnosis and outcome. Psychological Medicine, 22, 331-346.

Kuipers, E. (1996) The management of difficult to treat patients with schizophrenia, using non-drug therapies. British Journal of Psychiatry. 169 (Suppl.31), 41-51.

Larsen, T.K., Johannessen, J.O. \& Opjordsmoen, S. (1998). First-episode schizophrenia with long duration of untreated psychosis: Pathways to care. British Journal of Psychiatry, 172(Suppl.33), 45-52.

Lehman, A., Steinwachs et al. (1998). At issue: Translating research into practice: The schizophrenia patient outcome research team (PORT) treatment recommendations. Schizophrenia Bulletin, 24, 1-10.

Lehtinen, K. (1993) Need-adapted treatment of schizophrenia: A five year follow-up study from the Turku project. Acta Psychiatria Scandinavia. 87:96-101.

Lehtinen,V., Aaltonen, J. Koffert,T., Räkkölöinen,V., Syvälahti,E. \& Vuorio,K. (1996) Integrated treatment model for first-contact patients with a schizophrenia-type psychosis: The Finnish API project. Nordic Journal of Psychiatry. 50:281-287.

Lehtinen,V., Aaltonen,J., Koffert,T., Räkkölöinen,V. \& Syvälahti,E. (2000). Two year outcome in first-episode psychosis treated according to an integrated model. Is immediate neuroleptisation always needed? European Psychiatry, 15, 312-20

Liberman,R. (1993). Designing new psychosocial treatments for serious psychiatric disorders. Psychiatry, 56, 237-249.

Liberman, R. \& Green, M. (1992) Whither cognitive-behavioral therapy? Schizophrenia Bulletin. 18:27-35. 
Lieberman, J. (1997). Factors that influence the outcome of first-episode schizophrenia. Journal of Clinical Psychiatry Monographs, 15, 2-5.

Linszen, D.H, Dingemans,P, Scholte,W., Lenior,M. \& Goldstein, M. (1998). Early recognition, intensive intervention and other protective and risk factors for psychotic relapse in patients with first psychotic episodes in schizophrenia. International-Clinical-Psychopharmacology, 13(Suppl 1), S7-S12

Linszen, D.H, Lenior,M. De Haan, L., Dingemans,P \& Gersons, B. (1998) Early intervention, untreated psychosis and the course of early schizophrenia. British Journal of Psychiatry. 172(Suppl.33),84-89.

Loebel, A., Lieberman, J., Alvir, J., Mayerhoffer, D., Geisler, S. \& Szymanski, S. (1992). Duration of psychosis and outcome in first-episode schizophrenia. The American Journal of Psychiatry, 149, 1183-1188.

McFarlane, W., Link, B., Dushay, R., Matchal, J. \& Crilly, J. (1995a).

Psychoeducational multiple family groups: Four-year relapse outcome in schizophrenia. Family Process. 34,127-144.

McGorry, P. (1996). Psychoeducation in first-episode psychosis: A therapeutic process. Psychiatry, 58, 313-328

McGorry,P., Edwards,J., Mihalopoulos,C., Harrigan,S. \& Jackson,H. (1996). EPPIC: An evolving system of early detection and optimal management. Schizophrenia Bulletin, 22, 305-325.

McGorry, P., Henry, L., Maude, D. \& Phillips, L. (1998). Preventively orientated psychological intervention in early psychosis. In C. Perris \& P. McGorry (eds) Cognitive psychotherapy of psychotic and personality disorders: Handbook of theory and practice. John Wiley\&Sons.

Meeks, S. \& Murrell, S. (1994). Service providers in the social network of clients with severe mental illness. Schizophrenia Bulletin, 20, 399-406.

Mueser,K., Wallace, C. \& Liberman,R. (1995). New developments in social skills training. Behaviour Change, 12(1), 31-40.

Perris C. \& McGorry P.D. (eds.) (1998). Cognitive psychotherapy of psychotic and personality disorders. Chihester, John Wiley.

Salokangas, R., Räkköläinen, V. \& Stengård, E. (1991). Uusien skitsofreniapotilaiden hoito ja ennuste V: Viiden vuoden seuranta. Reports of Psychiatrica Fennica, 96. English summary.

Scottish-Schizophrenia-Research-Group (1992). The Scottish first episode schizophrenia study: VIII. Five-year follow-up: Clinical and psychosocial findings. British Journal of Psychiatry, 161, 496-500.

Seikkula, J.(1991) Family-hospital boundary system in the social network. English summary. Jyväskylä Studies in Education, Psychology and Social Research, 80 .

Seikkula, J., Aaltonen, J., Alakare,B., Haarakangas,K., Keränen, J. \& Sutela, M. (1995). Treating psychosis by means of open dialogue. In S. Friedman (ed.) The Reflective process in action. New York. Guilford Publication.

Seikkula, J., Alakare, B. \& Aaltonen, J. (1999). Potilaat sosiaalisissa verkostoissaan - kahden vuoden seurantatutkimus akuutin psykoosin kotihoidosta. In K. Haarakangas \& J. Seikkula (eds.) Psykoosi - uuteen hoitokäytäntöön. Helsinki. Kirjayhtymä.

Seikkula, J., Alakare, B. \& Aaltonen, J. (2001). Open dialogue in first-episode psychosis I: An introduction and case illustration. Journal of Constructivist Psychology, $\mathrm{x}, \mathrm{xx}-\mathrm{xx}$. 
Strauss, J.S. \& Carpenter, W. (1972). The prediction of outcome in schizophrenia. Archives of General Psychiatry, 27, 739-746.

Wirsching, W., Marder, S., Eckman, T., Liberman, R. \& Mintz J. (1992). Acquisition and retention of skills training methods in chronic schizophrenic outpatients. Psychopharmacology Bulletin, 28, 241-245.

Wyatt, R.J. (1997). Research in schizophrenia and the discontinuation of antipsychotic medications. Schizophrenia Bulletin, 23, 3-10.

Yung, A., Phillips, L., McGorry, P., Hallgren, M., McFarlane, C., Jackson, H., Francey, S. \& Pattor, G. (1998). Can we predict the onset of first episode psychosis in a high-risk group? International Clinical Psychopharmacology, 13 (Suppl 1), S23S30. 
TABLE 1.

The main principles of Open Dialogue (OD)

1) Immediate help. The teams arrange the first meeting within 24 hours of the first contact, made either by the patient, a relative or a referral agency. In addition to this, a 24-hour crisis service is set-up.

2) Social network perspective. The patients, their families, and other key members of their social network are always invited to the first meetings to mobilise support for the patient and the family. The other key members may be other authorities, including employment agencies and health insurance agencies in support of vocational rehabilitation, fellow workers or the head of the patient's work place, neighbors or friends.

3) Flexibility and mobility. These are guaranteed by means of adapting the treatment response to the specific and changing needs of each case using the most appropriate therapeutic methods. The first meeting is most often organized at the patient's home.

4) Responsibility. Whoever is first contacted is responsible for organizing the first meeting, in which the treatment decision is made. The team takes charge of the entire treatment process.

5) Psychological continuity. The team takes responsibility for the treatment for as long a time as needed in both outpatient and inpatient setting.

6) Tolerance of uncertainty. This is strengthened by means of building up a safe enough setting for the joint process. In psychotic crises, for an adequate sense of security to be generated means meeting every day, at least for the first $10-12$ days. In this way premature conclusions and treatment decisions are avoided.

7) Dialogism. The focus is primarily on promoting dialogue, and secondarily on inducing change in the patient or in the family. All issues are discussed openly while every one is present. 
Open dialogue -good and poor outcome 15

TABLE 2

Age, sex and premorbid adjustment of patients in the Poor and Good outcome groups at the onset of the crisis

\begin{tabular}{|c|c|c|c|c|c|c|c|}
\hline & $\begin{array}{l}\text { Poor } \\
\text { outcor }\end{array}$ & & $\begin{array}{l}\text { Good } \\
\text { outcor }\end{array}$ & & Total & & \\
\hline Variable & $\mathrm{N}=17$ & $\%$ & $\mathrm{~N}=61$ & $\%$ & $\mathrm{~N}=78$ & $\%$ & $\mathrm{p}$ \\
\hline Mean age & 27.7 & & 26.2 & & 26.5 & & ns \\
\hline Female & 7 & 41.2 & 24 & 39.3 & 31 & 39.7 & ns \\
\hline Male & 10 & 58.8 & 37 & 60.7 & 47 & 60.6 & \\
\hline \multicolumn{8}{|l|}{ Living } \\
\hline In family of origin & 10 & 52.8 & 32 & 52.6 & 42 & 53.8 & ns \\
\hline Alone & 3 & 17.6 & 9 & 14.6 & 12 & 15.4 & \\
\hline In own family & 4 & 23.5 & 20 & 32.8 & 24 & 30.8 & \\
\hline \multicolumn{8}{|l|}{ Employment status } \\
\hline Studying & 3 & 17.6 & 21 & 34.4 & 24 & 30.8 & $.001=$ \\
\hline Employed & 6 & 35.3 & 31 & 50.8 & 37 & 47.4 & \\
\hline Unemployed & 2 & 11.8 & 6 & 9.8 & 8 & 10.3 & \\
\hline $\begin{array}{l}\text { Passive without searching } \\
\text { for a job or living } \\
\text { on a disability allowance }\end{array}$ & 6 & 35.3 & 3 & 5.0 & 9 & 11.5 & \\
\hline \multicolumn{8}{|l|}{ Social network } \\
\hline Normal & 5 & 29.4 & $40 *$ & 76.9 & 45 & 65.2 & .001 \\
\hline Poor & 12 & 70.6 & 12 & 23.1 & 24 & 34.8 & \\
\hline
\end{tabular}

=Chi-square: Studying, Employed and Unemployed vs. Passive or disability allowance. $*$ : Missing data $=9$. 
TABLE 3

Psychological status of patients at the onset of the crisis in the Poor and Good outcome groups.

\begin{tabular}{|c|c|c|c|c|}
\hline Variable & $\begin{array}{l}\text { Poor } \\
\text { outcome } \\
\mathrm{N}=17 \%\end{array}$ & $\begin{array}{l}\text { Good } \\
\text { outcome } \\
\mathrm{N}=61 \%\end{array}$ & $\begin{array}{l}\text { Total } \\
\mathrm{N}=78 \%\end{array}$ & p \\
\hline \multicolumn{5}{|l|}{ Diagnosis } \\
\hline $\begin{array}{l}\text { Non-specified psychosis } \\
\text { with prodromal symptoms }\end{array}$ & 0 & 26.2 & 20.5 & \\
\hline Brief psychotic episodes & 0 & 27.9 & 21.8 & \\
\hline $\begin{array}{l}\text { Schizophreniform and } \\
\text { schizo-affective psychosis }\end{array}$ & 11.8 & 18.0 & 16.7 & \\
\hline Schizophrenia & 88.2 & 27.9 & 41.0 & $.001=$ \\
\hline \multicolumn{5}{|l|}{ GAF } \\
\hline -mean & 35.5 & 35.6 & 35.2 & ns \\
\hline -sd & 10.7 & 12.3 & 12.1 & \\
\hline \multicolumn{5}{|l|}{ BPRS } \\
\hline -mean & 49.1 & 43.5 & 45.3 & ns \\
\hline$-s d$ & 11.9 & 15.5 & 14.5 & \\
\hline \multicolumn{5}{|c|}{ Duration of psychotic symptoms/months before contact } \\
\hline - mean & 7.6 & 2.5 & 3.6 & .001 \\
\hline - sd & 7.6 & 4.1 & 5.3 & \\
\hline \multicolumn{5}{|c|}{ Duration of prodromal symptoms/months before contact } \\
\hline - mean & 26.7 & 7.0 & 12.6 & .001 \\
\hline - sd & 29.4 & 17.0 & 22.8 & \\
\hline
\end{tabular}


Open dialogue -good and poor outcome 17

TABLE 4

Treatment variables of the Poor and Good outcome groups during the two-year

follow-up period.

\begin{tabular}{|c|c|c|c|c|c|}
\hline & $\begin{array}{l}\text { Poor } \\
\text { Outcome }\end{array}$ & $\begin{array}{l}\text { Good } \\
\text { outcome }\end{array}$ & Total & & \\
\hline Variable & $\mathrm{N}=17 \%$ & $\mathrm{~N}=61 \quad \%$ & $\mathrm{~N}=78$ & $\%$ & $\mathrm{p}$ \\
\hline \multicolumn{6}{|l|}{ Hospitalization (days) } \\
\hline - mean & 47.5 & 9.0 & 18.8 & & 001 \\
\hline- sd & 56.0 & 19.2 & 36.3 & & \\
\hline \multicolumn{6}{|c|}{ Use of neuroleptic medication } \\
\hline Not used & 47.1 & 80.3 & 73.1 & & \\
\hline $\begin{array}{l}\text { Ongoing or discontinued } \\
\text { medication }\end{array}$ & 52.9 & 19.7 & 28.9 & & .001 \\
\hline \multicolumn{6}{|c|}{ Change in the social network of the patient $(\mathrm{N}=69)$} \\
\hline \multicolumn{6}{|c|}{ Good: } \\
\hline $\begin{array}{l}\text { Normal social network, } \\
\text { unchanged or developed }\end{array}$ & 5.9 & 67.3 & 52.2 & & \\
\hline $\begin{array}{l}\text { Poor at onset, } \\
\text { improved later }\end{array}$ & 11.8 & 11.5 & 11.6 & & \\
\hline \multicolumn{6}{|l|}{ Poor: } \\
\hline $\begin{array}{l}\text { Normal at onset, } \\
\text { impoverished later }\end{array}$ & 23.5 & 9.7 & 13.0 & & \\
\hline Poor throughout & 58.8 & 11.5 & 23.2 & $.001=$ & \\
\hline
\end{tabular}

= Chi-square: Good vs. Poor classes 